\title{
A PUBLICAÇÃO DE OS HERDEIROS E O CONTEXTO SOCIAL FRANCÊS*
}

\section{THE PUBLICATION OF THE WORK THE HEIRS AND THE FRENCH SOCIAL CONTEXT}

\begin{abstract}
Resumo
A publicação da obra Os herdeiros: os estudantes e a cultura, de Pierre Bourdieu e Jean-Claude Passeron, foi uma importante análise sobre as desigualdades do sistema educacional francês nos anos 1960. Do mesmo modo, a obra representa hoje a antecipação da Sociologia da Educação de ambos os autores. Apesar de que as análises foram empreendidas pelos dois sociólogos franceses, a sua construção é resultado da ampla participação de outros professores. À vista disso, este artigo visa apresentar o contexto de produção intelectual coletiva da obra explorando como se deu a participação na coleta de dados feita por pesquisadores e professores das diferentes instituições de ensino na França. Do mesmo modo, pretende-se analisar a influência do contexto social e econômico francês que, em ascensão, que resultou em investimentos nas pesquisas acadêmicas, propiciando a coleta de dados para a obra. O artigo também busca refletir sobre o contexto de após a sua publicação e seus desfechos diante das manifestações de Maio de 1968. Ademais, ressalta-se a importância das análises do livro para as investigações brasileiras, tendo em vista que, as desigualdades anunciadas pelos autores na década de 1960, apenas foram observadas, no Brasil, anos mais tarde, principalmente, em decorrência da expansão do ensino superior.
\end{abstract}

Palavras-chave: Contexto educacional francês; Desigualdade educacional; Educação; Maio de 1968.

\section{Abstract}

The publication of the work The Heirs: Students and Culture, by Pierre Bourdieu and Jean-Claude Passeron, was an important analysis of the inequalities of the French educational system in the 1960s. Likewise, the work today represents the anticipation of the Sociology of Education of both authors. Although the analyzes were carried out by the two French sociologists, their construction is the result of the wide participation of other teachers and professors. In view of this, this article aims to show the intellectual collective production context about the work (book) The Heirs: Students and Culture, exploring how the participation in collecting data of researchers and professors of different education institutions in France happened. social and economic context, which, on the rise, which resulted in investments in academic research, enabling data collection for the work. The article also seeks to reflect on the context of after its publication and its outcomes in the face of the May 1968 demonstrations. Furthermore, the importance of the book's analysis for Brazilian investigations is emphasized, considering that the

\footnotetext{
* Artigo Original: Recebido em 30/11/2019 - Aprovado em 28/09/2020.

${ }^{1}$ Graduada em Ciências Sociais e Mestra em Sociologia Política pela Universidade Federal de Santa Catarina. Doutorando do Programa de Pós-Graduação em Educação da Universidade Federal do Paraná, Curitiba/PR, Brasil. e-mail: luanalopes.cso@ gmail.com ORCID: https://orcid.org/0000-0001-7854-7928 (autor correspondente)
} 
inequalities announced by the authors in the 1960s, they were only observed in Brazil, years later, mainly due to the expansion of higher education.

Keywords: French university; Educational inequality; Education; May of 1968.

\section{Introdução}

Publicado originalmente em 1964 e com a tradução brasileira somente no ano de 2014 cinquenta anos após a primeira publicação - Os herdeiros, de Pierre Bourdieu e Jean-Claude Passeron, tornou-se uma obra de referência para o campo da Sociologia da Educação em razão da originalidade da pesquisa sobre o sistema de ensino francês quando, à época, puseram à vista os mecanismos operados pela instituição escolar a fim de estabelecer a manutenção da dominação social (BOURDIEU; PASSERON, 2014).

Embora tenham se passado mais de cinquenta anos após a publicação, ainda hoje, a tese acerca das desigualdades educacionais no ensino superior elaborada pelos sociólogos na década de 1960, é base para a análise e compreensão das copiosas faces da desigualdade nas universidades. É exatamente sobre a contemporaneidade da tese de Os herdeiros que Valle (2014), tradutora da versão em português da obra, argumenta sobre as razões para a sua leitura. Deste modo, afirma que, embora tenhamos todas as transformações sociais, econômicas e políticas na sociedade, o sistema de ensino preserva como valor universal a meritocracia - que enfatiza "dons naturais" e que vislumbra o acesso ao ensino superior como uma validação do mérito individual. Diante de tais considerações, Valle (2014) ressalta que a relevância da tese para compor as análises específicas do sistema educacional brasileiro ocorre em virtude de:

[...] termos um sistema de ensino, da educação infantil à educação superior, marcado por desigualdades que se cruzam e se multiplicam, impedindo dessa maneira de se vislumbrar, mesmo em longo prazo, um processo de escolarização o menos injusto possível. Nosso sistema de ensino se caracteriza por um fosso profundo entre os princípios que regem a educação nacional - a igualdade de oportunidades sendo o princípio norteador - e as desigualdades da oferta. (VALLE, 2014, p. 238).

As motivações para a leitura da obra não se restringem à originalidade do argumento sobre as desigualdades, incorporado à crítica ao sistema de ensino francês - que até aquele momento, proferia os ideais de uma educação democrática e igualitária. Tampouco, em razão do rompimento com a visão acerca da homogeneidade social e cultural dos estudantes franceses e, essencialmente, com a ideologia do dom. Assim sendo, destaca-se o peso epistemológico da obra que apresenta uma "síntese antecipada de toda a sociologia da educação de Pierre Bourdieu e Passeron" (NOGUEIRA; NOGUEIRA, 2015, p. 48), em razão de apresentar, em primeira mão e de forma introdutória, todos os conceitos que serão explorados durante a produção acadêmica dos autores. Os traços de conceitos estruturais para a teoria bourdieusiana - capital cultural, capital social, inculcação pedagógica - já aparecem na obra e são construídos sistematicamente em publicações futuras como, por exemplo, em A reprodução, publicada originalmente em 1970 (BOURDIEU; PASSERON, 1982).

Ademais, metodologicamente, Os herdeiros apresenta um novo modus operandi para a pesquisa sociológica francesa voltada para a Educação - até então, ensaística, ao inserir elementos empíricos - dados produzidos a partir de um levantamento estatístico elaborados pelo Institut Nacitional de la Statistique et des Étitudes Économiques (Instituto Nacional de Estatística e de Estudos Econômicos - INSEE) e Bureau Universitaire de Statistiques (Birô Universitário de Estatística - BUS) - em uma pesquisa longitudinal entre os anos de 1900 e 1963. A natureza dos dados levantados demonstrava:

[...] evolução do contingente bruto de estudantes universitários no período, sua distribuição por disciplina, universidade, sexo e origem social; as taxas líquidas de escolarização superior; dados sociológicos extraídos de monografias elaboradas por seus alunos 
das Universidades de Lille e de Paris sobre certas práticas e disposições dos estudantes universitários (NOGUEIRA; NOGUEIRA, 2015, p. 50)

Tal procedimento metodológico foi combinado com entrevistas, o que configura, para Faguer (2015, p. 37), uma obra de "caráter híbrido em sua forma" e possuidora de dois grandes objetivos, sendo o primeiro deles:

[...] um manifesto que se endereça ao público culto mais amplo do que o mundo dos sociólogos e dos filósofos; e o anúncio de um programa de trabalho que faz da sociologia da educação a base da análise de uma sociologia das classes (e de sua reprodução) da mesma forma que de uma sociologia dos intelectuais (FAGUER, 2015, p. 37).

Tendo em vista a relevância e contemporaneidade da obra, assim como, o valor epistemológico e metodológico da produção já retratados em outros estudos (VALLE, 2014; NOGUEIRA; NOGUEIRA, 2015, MASSON, 2016), não é o objetivo deste artigo uma leitura crítica das teses exploradas na obra, tampouco analisar a pertinência dos conceitos sociológicos apresentados. À vista disso, este artigo, de caráter ensaístico, pretende delinear, na primeira seção, a forma de produção de Os herdeiros, isto é, um trabalho coletivo entre professores de diferentes universidades, assistentes de pesquisa e com participação de jovens estudantes. A segunda parte tem como objetivo, apresentar o contexto social, econômico e político da época, que influenciou as análises sobre o sistema de ensino francês e a produção da obra. E, por fim, discorrer sobre as influências da publicação da obra em um dos movimentos mais significativos para a sociedade francesa, o Maio de 68.

\section{Os herdeiros: um trabalho coletivo}

Ainda que a produção final do relatório de pesquisa que originou a obra tenha sido realizada por Pierre Bourdieu e Jean-Claude Passeron, a construção da pesquisa foi feita por diferentes agentes. Os herdeiros é um produto final de um extenso trabalho de campo em diferentes universidades, que combinou diferentes instrumentos metodológicos, e a participação de inúmeros pesquisadores e assistentes de pesquisa.
Os dados foram colhidos por meio da aplicação de questionários aos estudantes, a qual ocorreu de maneira isolada, em grupos de trabalho ou por meio de indicações a partir redes de relações estudantis. Igualmente, em escala nacional, foram feitas análises de monografias e de dados estatísticos sobre a educação e o corpo discente, coletados e emitidos pelo INSEE e BUSS, cujas perguntas foram elaboradas especificamente para a produção da pesquisa (BOURDIEU; PASSERON, 2014) - procedimentos não realizados diretamente por Bourdieu e Passeron, mas que estavam sob suas orientações. As aplicações dos questionários aos alunos foram conduzidas por professores das diferentes universidades francesas, como Marcel Maget em Dijon; Guy Vincent em Lyon; Paul de Gaudemar em Toulouse; Jean René Tréanton em Lille e até mesmo realizando pesquisas próprias, como por exemplo, Marcel Maget, que analisou o uso do tempo pelos estudantes, e de Guy Vincent, sobre as atitudes dos estudantes face aos professores e ao ensino (ALMEIDA; PEROSA; ERNICA, 2015, p. 182).

Monique Saint-Martin, examinando o contexto e as operações das pesquisas de Os herdeiros, relatou a dificuldade de enumerar de maneira precisa todos os envolvidos em virtude das diferentes pesquisas relacionadas que naquele momento estavam em andamento e que fizeram parte desse grande resultado. Sociólogos atualmente reconhecidos, que na época ainda eram jovens estudantes ou assistentes de pesquisas, também participaram desse processo, por exemplo, Christian Baudelot, aluno de Bourdieu e Passeron que foi convidado a ingressar ao Centro de Sociologia Europeia e que suas primeiras incumbências estavam relacionadas aos cálculos de porcentagens estatísticas nas investigações que deram origem a Os herdeiros, como cita Baudelot em um trecho de entrevista "[...] meu primeiro trabalho, minha primeira 'ação' de sociólogo, foi servir de "faz-tudo" [grouillot], foi dar uma 'mãozinha' a Bourdieu e Passeron [...]” (ALMEIDA; PEROSA; ERNICA, 2015 p. 187).

\section{0 contexto social e econômico}

A produção de Os herdeiros se deve, sobretudo, ao contexto social francês da época. Naquele momento, a Sociologia da Educação estava se consolidando como uma disciplina científica ao 
projetar a educação e como um fortuito objeto de pesquisa (NOGUEIRA, 1995).

Maria Alice Nogueira (1990; 1995) apresenta um conjunto de fatores que contribuíram para a emergência e a consolidação da sociologia francesa. O primeiro deles é retratado, especificamente, entre o período de 1945 e 1965, um período pós Segunda Guerra Mundial que sucedeu um momento econômico de grande prosperidade perdurando por três décadas, conhecido como "os 30 gloriosos".

A conjuntura econômica otimista se dava por meio do aumento da produtividade nas indústrias, os ganhos reais do salário e por meio da transferência de renda pelo Estado para aqueles que se encontravam à margem do mercado de trabalho. Como efeito, o Estado francês passou a ocupar uma importante posição no desenvolvimento econômico, investindo em políticas de promoção de igualdade social e de aplicações em instrumentos estatais que garantissem a seguridade e proteção social na saúde e educação Etat providence - isto é, o cidadão teria assegurado pelo Estado francês as suas necessidades básicas. O conjunto de políticas sociais engendradas pelo Estado tinha a finalidade de reduzir o mal-estar social e contribuir para uma distribuição mais igualitária da renda, assegurando a estabilidade econômica. Os investimentos estatais na economia almejavam o desenvolvimento tecnológico em diversos setores, sendo o principal motivo para o aumento da produtividade. Em decorrência, tem-se a demanda de mão-de-obra qualificada "requerida pela rapidez dos avanços técnicos, o que inclui a necessidade em matéria de formação de quadros administrativos, burocráticos, científicos, técnicos, etc" (NOGUEIRA, 1990, p. 51).

Com a finalidade de suprir a nova demanda, a repercussão dos investimentos econômicos na Educação aconteceu de maneira direta: pela expansão das instituições escolares francesas e o prolongamento do ensino obrigatório. Esse crescente investimento estava associado ao retorno prático e, principalmente, econômico ao considerar - através de uma interpretação originária da economia clássica - a educação como o caminho para o desenvolvimento econômico.

O desafio enfrentado por políticos responsáveis pela economia da época era garantir que a França pudesse depender de uma força de trabalho altamente treinada, capaz ao mesmo tempo de modernizar a economia francesa e concorrer com economias rivais e altamente competitivas. [...] A qualificação é vista como um investimento com duas vantagens: garante o crescimento econômico e também vale a pena em termos individuais. (BAUDELOT, 2004, p. 17).

O segundo fator significativo que impulsionou a produção científica da sociologia francesa e dessa expansão da escolarização foi o considerável aumento populacional. O impacto da explosão demográfica, também conhecida como baby boom, no período pós Segunda Guerra Mundial, modificou significativamente a pirâmide etária populacional da França - fruto da prosperidade econômica e que representava a fonte de mudanças sociais e culturais importantes.

A preocupação das autoridades francesas concentrava-se na educação das crianças nascidas nesse momento, justamente pelas razões apontadas anteriormente: investimento em educação e o retorno econômico.

Esse contexto, de um lado, a explosão demográfica, as crianças que tinham nascido em 1947, 48, 49, chegaram aos anos 60, com 10 , 11 ou 12 anos, batendo às portas, portanto do ensino secundário. As sociedades enriqueciam, montando grandes máquinas de proteção social e estendiam o período escolar [...]. Esse contexto levou o aparecimento de grandes máquinas em que se constituíram os sistemas educacionais (NOGUEIRA, 1995, p. 26).

Masson (2016) explica que os altos investimentos econômicos em pesquisas durante os anos de 1950, 1960 e 1970, como o Centro de Pesquisas Sociológicas na Europa, criado em 1960 e comandado por Raymond Aron em parceria com Pierre Bourdieu e o Centro de Sociologia da Educação e da Cultura, sob a direção de Bourdieu nos anos 1970, favoreceram a contratação de técnicos de pesquisas e pesquisadores titulares, o que garantiu a produção de pesquisas específicas em Educação (ALMEIDA; PEROSA; ERNICA, 2015, p. 188). Diante do contexto, houve o favorecimento: 
[...] [da] produção simultânea, no mesmo centro e para um mesmo pesquisador, de grandes enquetes estatísticas, difíceis de se realizar sozinho. Portanto, esses meios constituem frequentemente oportunidades para relançar antigas enquetes e desenvolver novos projetos, e participam no desenvolvimento das atividades de um centro de pesquisa. Inúmeros sociólogos começaram sua carreira no início dos anos 1960 como pesquisadores temporários, depois como técnicos colaboradores, dos quais alguns, como Monique de SaintMartin, Yvette Delsaut e Michel Eliard, trabalharam sob a direção de Pierre Bourdieu e Jean-Claude Passeron. (MASSON, 2016, p. 117)

O objetivo era conhecer o perfil dos estudantes franceses que faziam parte desse momento de ampliação da educação, questionando quem é esse estudante? A partir disso, foi realizado um estudo longitudinal abrangendo um período de 10 anos que acompanhou 17 mil crianças que, no momento da pesquisa, cursavam o último ano da escola primária e, supostamente, passariam a ingressar à escola secundária. A pesquisa apresentou indicativos quantitativos acerca das desigualdades escolares presentes no sistema de ensino francês, a partir das categorias "idade, sexo, passado escolar, ocupação dos pais, lugar na fratria - que é algo que hoje a sociologia retoma [...] e habitat" (NOGUEIRA, 1995, p. 29).

No momento da produção destas pesquisas, o pensamento em voga era de que o estado francês construiu uma sociedade igualitária fundada em uma educação que supostamente teria o objetivo de equalizar as desigualdades sociais, em razão de ser uma escolarização obrigatória, pública e universal. Entretanto, tais certezas começam a apresentar suas fissuras. De fato, o sistema educacional francês proporcionou a democratização de acesso a seus estudantes se partirmos de uma análise quantitativa, considerando a idade de ingresso na escola e no tempo de permanência obrigatória na escolarização - em nenhum outro momento o sistema de ensino francês apresentou um número tão grande de matrículas. No entanto, a escolarização maciça surtia resultados desiguais para os estudantes quando analisados qualitativamente.
E a razão disso é que a realidade atestava que à expansão/ transformação do aparelho escolar não havia correspondido uma modificação das estruturas sociais, nem sequer uma redução significativa das desigualdades de oportunidades educacionais ou uma alteração importante das relações que cada grupo social mantém com a cultura escolar. Com efeito, o crescimento não beneficiava igualmente a todos, e o mito da igualdade de oportunidades e da democratização do ensino passou, então, a ser fortemente contestado a partir da década de 60 , bem como a visão da educação como um investimento produtivo própria dos economistas partidários da teoria do capital humano. O clima de otimismo cedia lugar ao desencanto (NOGUEIRA, 1990, p. 53).

Esses aspectos compunham uma tradução das desigualdades sociais em desigualdades escolares, que são apresentados e explorados por Pierre Bourdieu e Jean-Claude Passeron em Os herdeiros. $\mathrm{O}$ propósito não era o de elaborar um manifesto com a finalidade de rejeitar o sistema de ensino ou de se aliar frente a um pessimismo da educação, mas, sobretudo, comprovar que a educação francesa garantia e reproduzia as melhores posições no espaço social aos chamados herdeiros culturais, o que se mostrava muito distante da promessa de equalização social, devido às desiguais chances de acesso ao ensino superior pelos estudantes. Colocar em evidência as desigualdades no interior da instituição de ensino superior demonstrando que a parcela mais representativa de estudantes era composta por grupos oriundos das classes mais abastadas, era apontar exatamente aqueles que já contavam com maior representação e melhor posição no espaço social.

$\mathrm{O}$ alto investimento em educação e, consequentemente, as suas transformações, resultaram em problemáticas implicações sociais. Em certo momento, as desigualdades estavam relacionadas entre àqueles que ingressaram nas escolas médias ou no ensino superior e aqueles que ficaram à margem da escolarização. À medida em que se investiu na democratização do sistema escolar e que as instituições abriram suas portas para 
crianças e jovens de diferentes posições sociais, as desigualdades migraram para o interior do sistema de ensino. Essa perspectiva é explorada na obra conforme os sociólogos tecem análises acerca das categorias socioprofissionais das famílias dos estudantes franceses e indicam dissemelhanças entre as chances de acesso dos filhos de trabalhadores dos quadros profissionais menos favorecidos, dos que pertencem aos quadros médios e dos profissionais liberais. Para os primeiros, "as chances são apenas simbólicas de enviarem os filhos para a faculdade (menos de cinco chances em cem)", aos segundos fica reservado "de dez a quinze chances", ocorrendo a duplicação das chances reais para "quase trinta chances em um" e, por fim, os profissionais liberais contam com "chances de aproximadamente de sessenta em cem" (BOURDIEU; PASSERON, 2014, p. 17). Segundo os autores, é a herança cultural herdada da família de origem dos estudantes que influencia diretamente as trajetórias percorridas no interior da universidade, dispondo de maior influência até mesmo quando comparada às desigualdades de gênero e idade.

A tese de que há uma seleção prévia dos estudantes, relacionada com a manutenção da estrutura das classes sociais na França - posta em prática pela função social da escola e da cultura - é muito bem trabalhada no decorrer do primeiro capítulo da obra, denominado "A escolha dos eleitos". Os autores apresentam a reflexão de que as desigualdades são postas até mesmo na escolha dos cursos de graduação, afirmando ser essa "a forma mais oculta das desigualdades" (BOURDIEU; PASSERON, 2014, p. 16). Dentre os diversos dados estatísticos apresentados, a distribuição desigual entre os cursos de graduação é comprovada ao exporem que o aumento do número de matrículas ocorreu intensamente nos cursos de Ciências, Letras e gradualmente no curso de Farmácia em comparação dos cursos de Medicina e Direito. Segundo os autores:

Os estudantes das faculdades de letras e representam $65 \%$ da população estudantil, ainda que eles constituíssem somente um quarto no início do século. No mesmo período, as faculdades de direito e de medicina viviam uma evolução e simétrica inversa, a parcela da farmácia crescendo ligeiramente. (BOURDIEU; PASSERON, 2014, p. 113).
Deste modo, os estudantes eram distribuídos de forma desigual entre os cursos em razão de suas origens sociais - "Aqueles com uma origem mais modesta seriam afetados por aquilo que os autores chamam de uma "restrição de escolha", concentrando-se nos cursos de menor prestígio, como Letras e Ciências, em detrimento de opções como Medicina e Direito" (NOGUEIRA; NOGUEIRA, 2015, p. 51).

Apresentar as faces antagônicas do sistema de ensino francês foi, essencialmente, uma grande afronta às autoridades. O posicionamento contrário às explicações habituais de que o sucesso escolar estava aliado ao desenvolvimento individual que ignora totalmente as questões de privilégios sociais fornecem fundamentos científicos para as futuras mudanças sociais na França. A partir disso, análises acerca do mérito e igualdade real das oportunidades relacionadas ao capital cultural, social e econômico se constitui uma das teses centrais nos estudos da Sociologia da Educação.

\section{A tese de Os herdeiros assegurada pelas manifestações de Maio de 1968}

Os efeitos após a publicação da obra são tão significativos quanto o contexto que impulsionou a sua escrita. Jovens e crianças frutos da explosão demográfica e que se beneficiaram da expansão escolar no momento de prosperidade da sociedade francesa, como planejado, ingressaram nas instituições de ensino superior. Era uma nova geração que cresceu com o discurso e a promessa da equalização social e do conhecimento como o meio para a redução das desigualdades. Todavia, o momento contava com a instauração de uma desilusão com o sistema de ensino, por conta da massificação dos diplomas superiores.

Ao final dos anos de 1960, a sociedade francesa já se via diante de um decréscimo econômico - o que já ameaçava a promessa dos altos investimentos financeiros em educação e os resultados imediatos na economia - a expansão educacional acelerada - “de 207 mil universitários em 1956, a França saltaria para 505 mil alunos em 1967, num aumento de 143\%" (GROPPO, 2005, p. 554) - resultou em uma massificação e desvalorização dos diplomas e não mais garantia qualquer certeza de colocação no mercado de trabalho pelos egressos do ensino superior. Os estudantes começavam a sentir os 
efeitos do sistema de ensino elitista, já anunciados por Pierre Bourdieu e Passeron no início da década, e a questionar os ideais democráticos da universidade francesa, reconhecendo a função da escola para a conservação social e a crítica sobre as desigualdades e injustiças. Essa expansão do ensino atingiu igualmente aos professores, visto que:

Essa massificação leva o governo a contratar um grande número de novos professores. Assim, entre 1959 e 1967, o número de professores, de mestres de conferência e de mestres assistentes de letras e ciências humanas passa de 974 a 3.908. Isso também é acompanhado por uma mudança na estrutura dos empregos, o número de professores subalternos cresce muito mais rapidamente do que o dos professores, o que limita consideravelmente as possibilidades de carreira, tendo repercussões políticas importantes em maio de 68 (SOULIÉ, 2014, p. 44).

Simultaneamente, a França vivia um momento político e cultural em efervescência com os posicionamentos contrários às guerras do Vietnã, as discussões sobre as novas apropriações dos corpos, os concertos musicais etc. Para Saint-Martin:

[...] tornava-se claro ou mesmo evidente, sobretudo com os acontecimentos de maio 1968, que mudanças estavam acontecendo no sistema de ensino e que grupos importantes de estudantes e de professores eram favoráveis às transformações, o que não significa dizer que as forças conservadoras haviam desaparecido de uma hora para outra (ALMEIDA; PEROSA; ERNICA, 2015, p. 191).

Diante do contexto, os estudantes universitários descontentes com a conjuntura social francesa, em especial, com as contradições do sistema de ensino "rebelaram-se também contra as relações sociais autoritárias na Educação; as minorias étnicas contra a discriminação racial; as mulheres contra a divisão sexual do trabalho e outras formas de dominação masculina" (NOGUEIRA, 1990, p. 51) organizados nas manifestações de Maio de 68 que teve início na universidade de Nanterre.
Os protestos estudantis de Maio de 68 ultrapassaram os limites das universidades e chegaram às ruas, englobando as diferentes classes de trabalhadores.

Os acontecimentos que a França conheceu em maio e junho de 1968 , as manifestações e os motins estudantis duplicados pela maior greve geral da história francesa, tanto pela sua duração quanto pelo número de seus participantes, acompanhada pela ocupação de um número muito grande de locais de trabalho (usinas, lojas, escritórios, etc.), foram a expressão direta que provocou um sismo político de grande amplitude na própria França, percebido até mesmo além das fronteiras nacionais. Sismo cujas numerosas réplicas coloriram a crônica social e política francesa nos anos seguintes. (BIHR, 2007, p. 37)

O desfecho educacional das manifestações de 68 , que criticava todo o sistema tradicional da universidade, foi a implantação de centros universitários experimentais em Paris: "Dauphine, dedicada às ciências administrativas e implantada nos "bairros chiques" da capital, e Vincennes, um pouco isolada, construída no centro de um grande bosque parisiense, no caso o Bosque de Vincennes, e voltada às letras e às ciências humanas" (SOULIÉ, 2004, p. 45), estando Vincenne sob o comando de Pierre Bourdieu e Michel Foucault.

A finalidade da abertura de ambos os centros universitários era atender a uma das demandas das manifestações de 68 , propondo adentrar as inovações pedagógicas e científicas para o ensino superior e, para Soulié (2014), foi, igualmente, um jogo político na tentativa de afastar as tensões relacionadas à universidade e às contestações políticas do centro de Paris que estariam sendo direcionadas para as novas universidades mais afastadas.

A inovação da universidade de Vincenne era a construção de cursos heterodoxos e distantes dos moldes das salas de aulas tradicionais e acessíveis, o que levou a alguns impasses para a aquisição de alunos, como demonstra Soulié (2014), ao afirmar que aqueles estudantes que desejavam qualificarse para a docência, não se viam atraídos por aquela universidade. Donde, sem dúvida, a reticência a engajar-se por parte de uma parcela de estudantes e, sobretudo, os mais interessados na docência, 
que também são com frequência os mais dotados escolarmente e que, por isso, permaneceram nas universidades mais tradicionais (SOULIÉ, 2014).

O perfil estudantil da universidade no primeiro ano de existência era composto por estudantes com características militantes e, posteriormente, começou a receber um público que estava à margem dos bancos universitários:

[...] no caso, a de estudantes sem bacharelado e de assalariados. Graças, sobretudo, à multiplicação das aulas no período noturno, nos sábados, à grande flexibilidade dos seus cursos e às facilidades para se matricular, Vincennes atrai um público original. Assim, em 1975, ela conta com 38\% de estudantes sem bacharelado, $60 \%$ de assalariados em tempo integral. Em consequência, a média de idade dos estudantes de Vincennes passa de 27 anos em 1973-1974 para 29 anos em 1978-1979, contra 22 anos nas outras universidades francesas (SOULIÉ, 2014, p. 52).

A universidade não contava com todas as burocracias existentes em outras instituições para o ingresso - Vincenne tinha suas portas abertas formalmente. Inclusive, era conhecida por ser uma "Universidade aberta para todos" e "aos trabalhadores". Entretanto, desde Os herdeiros, tem-se o conhecimento de que a passagem pela universidade se converte em diferentes resultados para os diferentes agentes, deste modo, com a proposta de uma universidade aberta àqueles que tivessem interesse de frequentá-la, não seria diferente. Mais uma vez, a reflexão acerca da democratização do acesso se mostrou pertinente, visto que, estar na universidade é empreender um conjunto de disposições previamente adquiridas no meio de origem. As contradições quanto às composições sociais dos estudantes da Universidade de Vincenne ficaram evidentes quando "se compara a origem social dos estudantes de Vincennes com a dos estudantes das outras universidades, observa-se que, afinal de contas, ela está muito próxima. E que, como nas outras universidades, a admissão social se eleva à medida que se sobe no curso" (SOULÉ, 2014, p. 53).

Quando apurada a composição socioprofissional dos estudantes, concluiu-se que grande parte eram oriundos de profissões intermediárias e do setor terciário ou de carreiras educacionais e artísticas, indivíduos até então atípicos ao corpo discente universitário em razão de toda a sua característica elitista. Igualmente, pertenciam a grupos com heranças culturais, sociais, políticas, religiosas conturbadas o que tornavam ainda mais complexas as relações nas universidades pensadas para a classe operária e que foram frutos de Maio de 68, resultando na não consolidação acadêmica desses espaços e o fim daquela utopia.

\section{Conclusão}

Como exposto, Os herdeiros faz parte de uma reviravolta para a sociologia da educação francesa e que teve significativo respaldo em outros países, por conta do pioneirismo e originalidade de suas análises. Bourdieu e Passeron, em 1964, colocaram à vista as desigualdades presentes no interior do sistema de ensino francês que até então não haviam sido discutidas pelas pesquisas educacionais que apresentavam uma visão romântica e democrática da educação francesa. A concretude das análises se deu a partir da utilização de um rigoroso método científico com a combinação de diferentes instrumentos até então não utilizados pela Sociologia - e pela anunciação de importantes conceitos para a teoria das práticas sociais desenvolvida por Bourdieu em obras seguintes.

O desenvolvimento da importante tese do livro só foi possível diante do momento econômico e político francês que considerava importante o massivo investimento em pesquisas científicas que permitissem a compreensão da realidade educacional da França. Ainda que a tese tenha sido uma afronta às autoridades francesas, possibilitou novas reflexões e mudanças para o sistema de ensino.

É importante destacar a importância de Os herdeiros para compor análises sobre as desigualdades do ensino superior brasileiro, visto que, em 1964, os autores apresentavam as variações das desigualdades no ensino superior que somente passaram a fazer parte mais intensamente da agenda de pesquisa da Sociologia da Educação no Brasil, depois da implementação de uma série de políticas de democratização de acesso ao nível superior. $\mathrm{O}$ conjunto de pesquisas brasileiras desenvolvidas demonstram que, de fato, assim como na França dos anos 1960, o ingresso às universidades não é resultado do mérito dos estudantes. Do mesmo 
modo, unicamente democratização do acesso não é solução para o problema das desigualdades escolares, visto que, elas se apresentam como resilientes e se transformam na restrição da escolha dos cursos de graduação, que é orientada pela estrutura e volume de um conjunto de capitas e que está diretamente relacionada à desigual distribuição entre os cursos. Os herdeiros está presente quase que diariamente em artigos de jornais que tratam da mudança no perfil discente das universidades, das dificuldades enfrentadas por um estudante e por sua família para que ele pudesse ingressar em uma universidade pública ou privada, nas dificuldades que um estudante tem para manter-se na universidade, principalmente, em um curso de alta seletiva acadêmica e social ou nas reais chances de acesso de um estudante de escola pública no ensino superior.

\section{Referências}

ALMEIDA, Ana Maria F.; PEROSA, Graziela Serroni; ERNICA, Mauricio. Contribuição para uma história de Os Herdeiros - Entrevista com Monique de Saint-Martin. Educ. Soc., Campinas, v. 36, n. 130, p. 181-194, Mar. 2015.

BAUDELOT, Claude. As Qualificações aumentam, mas a desigualdade torna-se ainda maior. Proposições, v. 15, n. 2 (44), p. 15-38, maio/ago., 2004.

BIHR, Alain. Maio-junho de 1968 na França o epicentro de uma crise de hegemonia (parte I). Mediações, Londrina, v. 12, n. 2, jul./dez. 2007.

BOURDIEU, Pierre; PASSERON, Jean-Claude. A reprodução: elementos para uma teoria do sistema de ensino. 2. ed. Rio de Janeiro: Francisco Alves, 1982. Publicado originalmente em 1970.

BOURDIEU, Pierre; PASSERON, Jean-Claude. Os herdeiros: os estudantes e a cultura. Trad. Ione Ribeiro Valle e Nilton Valle. Florianópolis, 2014. Publicado originalmente em 1964.

FAGUER, Jean-Pierre. Os khâgneux de 68, objetos e leitores de Os Herdeiros. Educ. Soc., Campinas, v. 36, n. 130, p. 35-45, Mar. 2015.

GROPPO, L. A. Uma Onda Mundial de Revoltas: Movimentos Estudantis nos anos 1960. 2001. 559 f. Tese (Doutorado em Sociologia) - Instituto de Filosofia e Ciências Humanas, Unicamp, Campinas, 2001.

MASSON, Philippe. A produção de os herdeiros. Repocs, São Luís, v. 25, n. 13, p.105-136, jan. 2016.
NOGUEIRA, Claudio M. M.; NOGUEIRA, Maria Alice. Os Herdeiros: fundamentos para uma sociologia do ensino superior. Educ. Soc., Campinas, v. 36, n. 130, p. 47-62, Mar. 2015.

NOGUEIRA, Maria Alice. A sociologia da educação no final dos anos 60/ início dos anos 70: o nascimento do paradigma da reprodução. Em aberto, Brasília, ano 9, n. 46, abr. jun., p. 49-58, 1990.

NOGUEIRA, Maria Alice. Tendências atuais da Sociologia da Educação. Florianópolis, UDESC/ FAED, 1995.

SOULIÉ, Charles. Uma tentativa de democratização universitária na França: história da universidade de Paris VIII Vincennes (1968- 1980). Revista Linhas, Florianópolis, v. 15, n. 29, p. 232-250, jul./dez. 2014.

VALLE, Ione Ribeiro. Os herdeiros: uma das principais "teses" da sociologia francesa da educação. Revista Linhas, Florianópolis, v. 15, n. 29, p. 42-70, jul./dez. 2014. 